\title{
Students' Responses to Tutor Feedback: Focusing on Their Writing and Perceptions
}

\author{
Sookyung Cho \\ sookyungcho@hufs.ac.kr \\ Hankuk University of Foreign Studies, Korea \\ Chanho Park (Corresponding Author) \\ cpark.irt@gmail.com \\ KeimyungUniversit, Korea
}

\begin{abstract}
Studies on students' responses to tutor feedback have been conducted in large scales, in particular, focusing on students' perceptions of tutor feedback. However, few of these studies have examined how students respond to tutors' written feedback in their writing. In order to broaden the understanding of a student's response to a tutor's feedback, this study examines tutors' written feedback, students' writings, and their perceptions of the feedback. Based on this examination, this study aims to see what types of tutor feedback do students incorporate in their revisions and what the students think of tutor feedback. The participants were 11 tutors and 18 college students. Each student received tutor feedback on two writing assignments - a compare-and-contrast essay and an argumentative essayand filled out a questionnaire that asked about their experiences with the feedback they received. The analysis of students' writing and tutor feedback reveal that error type and feedback type seem to affect a student's incorporation of feedback; in particular, students incorporated content-oriented, indirect, and coded types of feedback more than the other feedback types. The questionnaire data show that most students valued the tutor feedback; however, low incorporators had more problems in incorporating tutor feedback. Based on these results, suggestions on tutor feedback and implications for future studies are discussed.
\end{abstract}

Keywords: student response; tutor feedback; incorporation of feedback; feedback type; feedback style

\section{INTRODUCTION}

The system of using tutors in assisting classroom teachers has been widely adopted in many areas of academic settings in English-speaking countries, such as the United States and the United Kingdom. It has often been reported that in comparison with teachers who are in charge of the classes, tutors have more equal and flexible relationships with their students. Harris (1995) reported that students feel more comfortable with tutors than with their teachers. Others reported that students can negotiate meanings with their tutors more than they can with their teachers (Aljaareh \& Lantolf, 1994; Cho \& Kim, 2017; Goldstein \& Conrad, 1990; Williams, 2004). That is, while a teacher deals with a large number of students in one class and has more difficulties customizing his or her comments to each student, tutors can make their feedback tailored to a student's needs. Studies on tutor feedback have revealed that because of their awareness of the advantages that tutor feedback have on them, students seem to value tutor feedback (Hyland, 2013; Nicol \& MacFarlane-Dick 2006; Sadler, 1989; Sendziuk, 2010; Taras, 2003, 2006;). These studies were mostly conducted in the framework of formative assessment, that is, assessment of the students' learning, and arrived at a similar 
conclusion that tutor feedback provides students with more opportunities to improve their performances on their own by enhancing their understanding of strengths and weaknesses.

Unfortunately, however, the studies that have explored the issue of how students respond to tutor feedback have mostly focused on a student's perceptions on tutor feedback by conducting a survey or a questionnaire in a large scale (Hyland, 2013; Sadler, 1989; Sendziuk, 2010; Taras, 2003, 2006). They have rarely examined the tutor feedback or the student's writing based on the feedback they received. In order to fill in this gap, this study aims to investigate students' responses to tutor feedback in their writing assignments as well as in their perceptions of the feedback. This study examines the tutors' written feedback, the students' incorporation of the feedback in their revisions, and their responses to the questionnaires on their experiences regarding tutor feedback. With this examination, this study explores students' writings as well as their perceptions in order to answer the following questions:

1) What types of tutor feedback do students incorporate in their revision? How do error type and tutor feedback style affect student incorporation?

2) How do high and low incorporators of tutor feedback differ in their perceptions on it?

\section{LITERATURE REVIEW}

To date, many scholars who have been interested in tutor feedback have studied tutor feedback from the tutors' points of views: how they think of their feedback and what type of feedback they provided (Bloxham \& Boyd, 2012; Court \& Johnson, 2016). For example, Bloxham and Boyd (2012) investigated think-aloud protocols of 12 tutors from various disciplines - teacher education, history, English literature, business studies, and performing arts. They found that all the tutors believed that there were established and shared academic standards of student attainment in each of their disciplines and thus they tried to adhere to them in giving feedback to their students. On the other hand, Court and Johnson (2016) investigated what aspects of writing tutors focus on in their feedback and why they do that. After analyzing five tutors' feedback and interviewing the tutors, Court and Johnson found that there are individual variations in their feedback styles and that their personal beliefs on academic writing seem to affect their feedback styles: those who were affiliated with academic writing for learning provided comments on grammar as well as content, whereas those who believed that students should be familiar with academic discourse practices tended to give content-oriented feedback.

While the previous studies focused on tutors' perspectives when giving feedback, there have been some approaches that try to see tutor feedback from the recipients' points of view, i.e., how students respond to tutor feedback (Hyland, 2013; Nicol \& MacFarlane-Dick 2006; Sadler, 1989; Sendziuk, 2010; Taras, 2003, 2006). The results of most studies are quite positive: students seem to value tutor feedback. Within the framework of formative assessment - designed to facilitate student learning unlike summative assessment of which the goal is to evaluate student achievement - tutor feedback has often been considered an essential part of improving students' abilities to self-assess their abilities. For example, Sendzuik (2010) developed a learning-oriented assessment task for his history class and included the process of tutors providing feedback on students' essays before giving them grades. After finding that this assessment task helped the students to self-assess their abilities better, Sendzuik argued that tutor feedback facilitates students' understanding of grading rubrics and criteria, and eventually improves their works. Similarly, within the framework of self-assessment, Taras (2003 and 2006) also emphasized the importance of tutor feedback. In her 2003 study, Taras compared two types of self-assessment - one conducted without tutor 
feedback and the other conducted with tutor feedback-among English native speakers in their translation tasks from English to French. Based on the finding that most students preferred self-assessment with tutor feedback, Taras (2016) suggests that one of the greatest advantages is that tutor feedback makes students "realise what their true strengths and weaknesses were, as opposed to the presumed or expected weaknesses. This suggestion was informative for both students and tutors and helped focus energies where work was really needed" (p. 561). Taras (2016) noticed anomalies that some undergraduate students facedthey received much less feedback on their writings and were not taught how to incorporate even a small amount of feedback, compared to postgraduate students and faculty members. Thus, she made several suggestions to solve these anomalies; and one of them is to provide undergraduate students with opportunities to integrate tutor feedback into assignments that do not lead to their final grades. She believed this would help students develop an understanding of standards and criteria in essay writing.

Unlike the positive views that students have on tutor feedback, several scholars have warned about the problems and concerns regarding tutor feedback from the students' points of views (Hyland, 2013; Orsmond \& Merry, 2010; Weaver, 2006). For example, Weaver (2006) surveyed 24 students from Business and 20 from Art and Design on their perceptions of tutor feedback and found that the majority of the students had difficulties in clearly understanding tutor feedback. Also, although they wholeheartedly believed in the value of tutor feedback, they doubted its effectiveness. In particular, Weaver's(2006) qualitative analysis of students' responses reveals that students indicate vagueness, lack of guidance, focus on the negative, and irrelevance to assessment criteria as the four major features of unhelpful feedback. By focusing on tutor's written feedback and semi-structured interview data both with tutors and students, Orsmond and Merry (2011) also found that there is a misalignment between tutors' and students' understanding of feedback; students often failed to deal with tutor feedback for their future improvement as learners in their own disciplines; instead they aimed the feedback to their particular piece of work. Hyland (2013) similarly argued that there is a lack of understanding of tutor feedback among students. After interviewing 24 first- and second-year undergraduate students to see what they think of tutor feedback, Hyland (2013) found that students often separated tutor feedback from its context and had impressions that academic writing is an abstract and autonomous entity. To the students, "academic literacy is an abstract and relatively self-evident style of writing unrelated to particular academic communities" (Hyland, 2013, p. 186).

As discussed, these studies that examined the issue of how students respond to tutor feedback - whether the students had positive or negative responses to tutor feedback, are limited in that they only focused on students' perceptions on it, which were usually gleamed through surveys or questionnaires. There are only few studies that investigate how students actually use tutor feedback in their revisions. Hence, this study aims to examine how students incorporate tutor feedback in their revised writing, in particular, to investigate whether students' error type and tutor's feedback style affect their incorporation. According to Ferris (2006), error type - i.e., what types of grammatical errors a particular feedback points outand feedback style - i.e., how the error is pointed out, directly or indirectly - have often been used as an analysis tool to classify teachers' written feedback. Finally, this study hopes to explore how high and low incorporators of tutor feedback think of tutor feedback by comparing their perceptions on tutor feedback. 


\section{METHOD}

\section{PARTICIPANTS AND DATA COLLECTION}

In order to answer the research questions, three different types of data were collected for this study - tutor feedback, student essays, and their answers to a questionnaire. The tutor feedback came from 11 tutors who were enrolled in a graduate school at a university located in Seoul, Korea. They were trained as tutors through a graduate seminar course, which aimed at teaching the graduate students how to give feedback to English language learners. Student essays were written by 18 college students who took an English writing course offered to first year students at the same university. During this particular semester, which is Fall 2017, the 18 students wrote 33 pieces of academic essays in total-16 cause-and-effect essays and 17 argumentative essays, and they received feedback from two different tutors on each of their essays. All the 11 tutors and 18 students volunteered to participate in this study. The tutors either met with the students face-to-face or communicated with them by email, depending on their students' preferences. Out of the 11 tutors, three met with the students face-to-face whereas the others gave their feedback by email. Copies of their written feedback were collected from the tutors while revisions that incorporated the tutor's feedback were collected from the students. Most tutors gave their feedback fully in Korean, except for four-two of them used English fully while the other two code-switched between Korean and English.

Additionally, at the end of the semester, a questionnaire was distributed to the students to investigate what they thought of the tutor feedback. Out of the 18 students, three did not come to the last class, so only 15 students completed the questionnaire. The questionnaire consisted of five questions - how useful the tutor feedback was in revising their drafts, which tutor was more helpful out of the two tutors, what problems they had in incorporating the tutor feedback, how they solved these problems, and what suggestions they would have for the future use of tutor feedback in a writing class. The questionnaire was completed in Korean based upon the assumption that students would be able to express their thoughts more freely in their native language than in English. Since all of the questions were open-ended, the answers to these five questions were analyzed qualitatively through a thematic analysis.

\section{DATA ANALYSIS}

First, in order to see whether error type and feedback style affected students' incorporation of tutor feedback, all the tutors' written feedback were classified depending on error type and feedback style. Ferris' (2006) classification with slight modifications was adopted. Since the students were taught how to use outside sources, (e.g., books, magazines, newspaper articles, or academic journals) in their writing class and that they were also required to incorporate what they have learned in class in their writing, new categories such as "evidence," "voice," or "citation" were added as categories of error type to the framework of Ferris. Table 1 shows the categories of error type.

TABLE 1. Error Type (Adapted from Ferris, 2006)

\begin{tabular}{lll}
\hline Error Type & Description & Example \\
\hline Word Choice & Wrong word choice & "global" to "official" \\
Verb Tense & Verb tense & "were" to "had been" \\
Verb Form & Verb form & "is started" to "starts" \\
Word Form & Word form & "not" to "no" \\
Article & Article & "a" to "the" \\
Singular-plural & Singular-plural & "evidences" to "evidence" \\
Pronoun & Pronouns & "he" to "s/he" \\
\hline
\end{tabular}




\begin{tabular}{|c|c|c|}
\hline Run-on & Comma splices & $\begin{array}{l}\text { "Youtube helps creators } \sim, \\
\text { Youtube Korea could be } \sim \text {." (run- } \\
\text { on) }\end{array}$ \\
\hline Punctuation & $\begin{array}{l}\text { Commas, periods, semicolons, and } \\
\text { colons }\end{array}$ & "." to “;” \\
\hline Fragments & Incomplete sentences & "sentence fragment" \\
\hline Spelling & Includes capital and small letters & "sympton" to "symptom" \\
\hline Error Type & Description & Example \\
\hline Sentence Structure & $\begin{array}{l}\text { Includes missing and unnecessary } \\
\text { words, phrase, and word order } \\
\text { problems; teacher changed sentences to } \\
\text { read more naturally }\end{array}$ & $\begin{array}{l}\text { "the problem of insomnia is that it } \\
\text { can undermine } ~ \text { " to "the problem } \\
\text { of insomnia can undermine } \sim "\end{array}$ \\
\hline Voice & $\begin{array}{l}\text { Refers to register choices considered } \\
\text { inappropriate for academic writing }\end{array}$ & "Too informal!" \\
\hline S-V agreement & Subject-verb agreement & "were" to "was" \\
\hline Adverb & Adverb & "he may (finally) quit school" \\
\hline Preposition & Prepositions & "from" to "into" \\
\hline Contents & Comments on topic and theme & “Any final remarks?” \\
\hline Off-topic & Comments on unity & "Off-topic!" \\
\hline Clarification & $\begin{array}{l}\text { Comments on unclear contents and } \\
\text { terms }\end{array}$ & "Not clear!" \\
\hline Elaboration & Asks for further explanations & "Why in England?" \\
\hline Coherence & $\begin{array}{l}\text { Transitions from one to another } \\
\text { sentences }\end{array}$ & $\begin{array}{l}\text { "Do these sentences make a causal } \\
\text { relationship?" }\end{array}$ \\
\hline Organization & $\begin{array}{l}\text { Comments on paragraph and essay } \\
\text { structures }\end{array}$ & $\begin{array}{l}\text { "You can combine these three } \\
\text { paragraphs into your conclusion." }\end{array}$ \\
\hline Conjunction & Conjunctions & "if" to "because" \\
\hline Citation & $\begin{array}{l}\text { Comments on sources of outside } \\
\text { materials used in the essay }\end{array}$ & "(Sin)" \\
\hline Repetition & Repeated words or contents & "Repeated words" \\
\hline Evidence & Request of more supporting details & "Any evidence?" \\
\hline
\end{tabular}

Based on Ferris (2006), tutor feedback was also classified into eight different feedback styles as shown in Table 2. The distinction between direct or indirect feedback was determined by the factor whether the tutor provided a corrected answer directly or not. Coded or not-coded refers to the distinction whether the tutor explained what is wrong or not. Finally, direct error location and indirect error location are feedbacks written in margin, but their distinction depends on whether they indicate the location of errors or not.

TABLE 2.Feedback Style (Adapted from Ferris, 2006)

\begin{tabular}{|c|c|c|}
\hline Feedback Style & Description & Example \\
\hline Direct & Indicate errors and correct them & "This shows the fact that $\sim$ \\
\hline Direct-coded & $\begin{array}{l}\text { Indicate errors, correct them, and } \\
\text { categorize them }\end{array}$ & $\begin{array}{l}\text { "the insomnia (The is not used in } \\
\text { front of the word insomnia.)" }\end{array}$ \\
\hline Indirect & Indicate errors, but do not correct them & "(Kim, Y. H.)" \\
\hline Indirect-coded & $\begin{array}{l}\text { Indicate errors, categorize them, but do not } \\
\text { correct them }\end{array}$ & $\begin{array}{l}\text { "the professional enterprise are } \\
\text { going to a café." (You need to } \\
\text { match the subject with its } \\
\text { appropriate verb form)" }\end{array}$ \\
\hline Direct error location & Explain error location in margin & $\begin{array}{l}\text { (in margin) Grammar! Third } \\
\text { paragraph, line number } 10\end{array}$ \\
\hline Direct error location-coded & $\begin{array}{l}\text { Explain the location of errors and } \\
\text { categorize them in margin }\end{array}$ & $\begin{array}{l}\text { (in margin) Grammar! Third } \\
\text { paragraph, line number } 10 . \text { You } \\
\text { should change the word. }\end{array}$ \\
\hline Indirect error location & No explanation of error location in margin & (in margin) Grammar! \\
\hline $\begin{array}{l}\text { Indirect error location- } \\
\text { coded }\end{array}$ & $\begin{array}{l}\text { No explanation of error location, but } \\
\text { categorization of the errors in margin }\end{array}$ & $\begin{array}{l}\text { (in margin) Grammar! You should } \\
\text { focus on the word choice. }\end{array}$ \\
\hline
\end{tabular}


Both the researchers of this study coded the tutor feedback; differences were discussed until an agreement was met for the classification of all error types and feedback styles.

Once the classification was done, students' first and revised drafts were meticulously compared and contrasted by both the researchers to determine whether this feedback was incorporated or not. The task of determining whether the feedback was incorporated or not, was not easy because often there were cases when students did not accept the feedback the way their tutor had suggested. Hence, only the instances of feedback that both the researchers agreed was incorporated exactly as the tutor suggested were counted as cases of incorporation. The ratio - the total number of incorporation cases divided by the total number of each error and feedback style - was calculated for each individual student's writing assignments. In order to identify students' preference of tutor feedback by error type and feedback style, categories in both error type and feedback style were merged into bigger ones-contentoriented vs. grammar-oriented ones for error type, coded vs. uncoded, and direct vs. indirect for feedback style - and a series of $\chi^{2}$ tests with Yates' continuity correction was performed in R (R Core Team, 2018).

Finally, the students were divided into high incorporators and low incorporators depending on whether their incorporation rate of the tutor feedback were above or below the average score. Out of the fifteen who completed the questionnaire, six were classified as high incorporators above the average 0.3678 - which means they incorporated more than 3 out of 10 incidents of tutor feedback - whereas the other nine were grouped into low incorporators, whose ratios were below the average score. Their open-ended answers were first coded line by line, and these codes were grouped into similar topics to identify emerging themes in the questionnaire. Later, they were compared and contrasted depending on high versus low incorporators. Once the themes were identified, the written answers were read and compared against these themes to see whether or not they were congruent with each other.

\section{RESULTS}

\section{STUDENT INCORPORATION BY ERROR TYPE}

The analysis of tutor feedback by error type shows that the tutors were most likely to give feedback on sentence structures in students' essays, followed by word choices, contents, article, and punctuation, as shown in Table 3. They rarely gave feedback on error types such as idioms, run-ons, verb complements and spellings.

TABLE 3. Descriptive Statistics for Tutor Feedback by Error Type

\begin{tabular}{llccc}
\hline & Item & Total & Incorporated & Ratio \\
\hline Grammar-Oriented & Sentence Structure & 121 & 23 & 0.1901 \\
& Word Choice & 83 & 22 & 0.2651 \\
& Punctuation & 55 & 19 & 0.3455 \\
& Article & 55 & 16 & 0.2909 \\
& Conjunction & 90 & 5 & 0.2250 \\
& Preposition & 40 & 13 & 0.1250 \\
& Plural & 29 & 9 & 0.4483 \\
& Citation & 28 & 4 & 0.3214 \\
& Verb Tense & 24 & 4 & 0.1667 \\
& S-V & 24 & 6 & 0.1667 \\
& Pronoun & 23 & 8 & 0.2609 \\
& Fragment & 21 & 8 & 0.3810 \\
& Repetition & 19 & 9 & 0.4211 \\
Capital & 16 & 0.5625 \\
\hline
\end{tabular}




\begin{tabular}{llccc}
\hline & Voice & 15 & 2 & 0.1333 \\
& Word Form & 14 & 2 & 0.1429 \\
& Adverb & 14 & 1 & 0.0714 \\
& Verb Form & 13 & 1 & 0.0769 \\
& Spelling & 10 & 4 & 0.4000 \\
& Complement & 10 & 3 & 0.3000 \\
& Run-on & 1 & 1 & 1.0000 \\
& Idiom & 1 & 0 & 0.0000 \\
Content-Oriented & Contents & 68 & 31 & 0.4559 \\
& Elaboration & 49 & 16 & 0.3265 \\
& Clarification & 36 & 11 & 0.3056 \\
& Off-Topic & 31 & 8 & 0.2581 \\
& Coherence & 25 & 13 & 0.5200 \\
& Evidence & 16 & 6 & 0.3750 \\
& Organization & 12 & 5 & 0.4167 \\
\hline
\end{tabular}

In general, the ratio by which the students incorporated tutor feedback of each error type in their revisions does not necessarily correspond with its frequency; in other words, it does not necessarily mean that the more a particular type of feedback is given, the more it is incorporated by the students in their revisions. However, it seems that the content-oriented feedback (feedback that points out problems beyond a sentence level, henceforth, Content) were incorporated relatively more than the grammar-oriented ones (feedback that points out grammatical mistakes within a sentence, henceforth, Grammar). For example, feedback on coherence was incorporated more often into students' revisions than feedback on sentence structure and word choice; although Sentence Structure is the most frequently-given feedback (121 incidents), its incorporation ratio (0.1901) is not as high as that of Coherence (0.5200), which the tutors pointed out much less (25 incidents). Likewise, Word Choice is the secondmost frequently-given feedback by the tutors (83), but its incorporation by the students in their writing is ranked $17^{\text {th }}$, which is lower than other less frequently-given feedback such as Contents, Elaboration, or Clarification. In order to see whether this difference between Content and Grammar types of tutor feedback is statistically meaningful, a $\chi^{2}$ test with Yates' continuity correction was conducted (See Table 4). The results show that the difference between Grammar and Content is statistically significant at the level of $0.05\left(\chi^{2}=12.024, d f\right.$ $=1, p=0.00$ ), which means, students incorporated tutor feedback on Content (e.g., Contents, Elaboration, Off-topic, Clarification, Coherence, and Evidence) more than feedback on grammatical mistakes.

TABLE 4. Chi-Square Table for Error Type

\begin{tabular}{lccc}
\hline & Incorporated & Unincorporated & Sum \\
\hline Grammar & 169 & 487 & 656 \\
Content & 90 & 147 & 237 \\
Sum & 259 & 634 & 893 \\
\hline
\end{tabular}

\section{STUDENTS' INCORPORATION BY FEEDBACK STYLE}

The analysis of tutor feedback by its style shows that the majority of tutor feedback was direct, which means, tutors preferred to correct errors in student essays. Table 5 shows that Indirect-Coded was the second-most provided type of feedback; that is, instead of correcting the errors directly, tutors explained what was wrong so that students could correct the errors themselves. 
TABLE 5. Descriptive Statistics for Tutor Feedback by Feedback Style

\begin{tabular}{llccc}
\hline & Item & Total & Inc. & Ratio \\
\hline 1 & Direct & 415 & 91 & 0.2193 \\
2 & Indirect-Coded & 269 & 102 & 0.3792 \\
3 & Indirect & 83 & 19 & 0.2289 \\
4 & Direct-Coded & 68 & 24 & 0.3529 \\
5 & Direct Error Location-Coded & 30 & 11 & 0.3667 \\
6 & Indirect Error Location-Coded & 22 & 9 & 0.4091 \\
7 & Direct Error Location & 6 & 3 & 0.5000 \\
8 & Indirect Error Location & 0 & 0 & 0.0000 \\
\hline
\end{tabular}

Note. The highlighted ones are content-oriented feedback while the others are grammar-oriented feedback

Tutors preferred to point out errors in the margin without categorizing them the least. Whether they indicated the error locations (Direct Error Location) or not (Indirect Error Location), they rarely gave feedback without explaining what was wrong in the student's essay. For example, Figure 1 shows each case of direct error location and direct error location-coded feedback. In the first case, tutor "Yumi" gave a direct error location feedback by correcting the article error from "majority of Koreans" to "a majority of Koreans" without any explanation. However, in the second instance, she provided a direct error location-coded feedback by adding the explanation why the tense should be present, not present progressive. Out of all the seven feedbacks Yumi gave in the margin, four of them are coded ones like the second case.

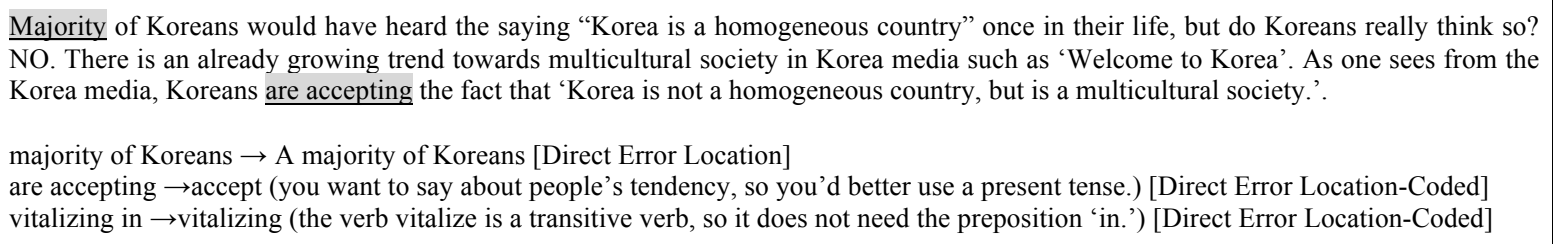

FIGURE 1. Direct Error Location-Coded vs. Direct Error Location

As in the case of error type, students' incorporation ratio of this type of tutor feedback is not necessarily in line with its frequency. Although direct feedback was the most-preferred way of giving tutor feedback among tutors, Table 5 shows that students did not seem to prefer this type of feedback in a great deal, as confirmed in their low incorporation rate (0.2193). Interestingly, Direct Error Location, the least frequently-given type of feedback next to Indirect Error Location, shows the highest incorporation rate (0.5) out of the 8 categories. This result implies that students were likely to accept the feedback most when the tutors explained the location of errors in the margin without categorizing them into specific types of errors. The other two types - Indirect Error Location-Coded and Indirect-Codedshow similar ratios of incorporation to each other (0.4091 and 0.3792), second and third highest respectively next to Direct Error Location. Their incorporation ratios are higher than those of their direct counterparts such as Direct Error Location-Coded (0.3667) and DirectCoded (0.3529). This result may indicate that in their revisions, students were inclined to accept more indirect types of tutor feedback than the direct ones. Also, the four coded types of feedback-Indirect Error Location-Coded, Indirect-Coded, and Direct-Coded - seem to be incorporated by the students relatively more than their other uncoded counterparts.

In order to see whether there are statistically significant differences between indirect and direct types of feedback and between coded and uncoded types of feedback, chi-squared tests with Yates' continuity correction were conducted. Based on these tests, both the differences between coded and uncoded and between direct and indirect types of feedback are 
statistically significant $\left(\chi^{2}(1)=23.619, p=.00\right.$ for coded and uncoded; $\chi^{2}(1)=9.8787, p$ $=.00$ for direct and indirect). This suggests that students had a tendency to incorporate tutors' coded feedback more than the uncoded ones and tutors' indirect feedback more than the direct ones, although the tutors tended to give direct feedback more often than indirect ones and uncoded feedback more often than coded ones.

TABLE 6. Chi-Square Table for Feedback style (Coded vs. Uncoded)

\begin{tabular}{lccc}
\hline & Incorporated & Unincorporated & Sum \\
\hline Uncoded & 113 & 391 & 504 \\
Coded & 146 & 243 & 389 \\
Sum & 259 & 634 & 893 \\
\hline
\end{tabular}

TABLE 7. Chi-Square Table for Feedback style (Direct vs. Indirect)

\begin{tabular}{lccc}
\hline & Incorporated & Unincorporated & Sum \\
\hline Direct & 129 & 390 & 519 \\
Indirect & 130 & 244 & 374 \\
Sum & 259 & 634 & 893 \\
\hline
\end{tabular}

\section{HIGH VS. LOW INCORPORATORS' PERCEPTIONS ON TUTOR FEEDBACK}

The analysis of the responses to the questionnaires on tutor feedback reveals that most students - no matter how much they incorporated tutor feedback - answered quite positively to the question whether or not tutor feedback was useful in helping them to revise their draft. Five out of the 15 participants who answered the questionnaire, mentioned that tutor feedback helps with their weak areas in essay writing. Their responses are as follows (italics indicate the author's emphasis. All the names are pseudonyms):

Tutors corrected what I have missed as a writer (such as expressions, organizations, and appropriateness of examples) from an impartial point of view.

(Minwoo)

I have always been very concerned whether my English expressions sound awkward because of my lack of English writing ability. The tutor pointed out these kinds of problems.

(Jiyeon)

I wanted to receive feedback on whether I was on the right track in using appropriate evidence to support my opinion while writing the argumentative essay and the compareand-contrast essay. Tutors were helpful in that sense because they pointed out pitfalls in my logic from a new perspective.

(Hanna)

As seen in the excerpts, the participants stated that tutor feedback helped to fulfill their weak or lacking spots, which they referred to using terms such as "what I have missed" as in the case of Minwoo, "lack" in Jiyeon, and "pitfalls" in Hanna.

As for another advantage of tutor feedback, the participants often mentioned that tutor feedback helps them read their essays from a new perspective.

Tutor feedback was helpful for me in writing my essay because they provided a third person's perspective and suggested how to improve my essay.

(Sumi)

I liked the tutor feedback because I could hear honest opinions of others about my essay and eventually, I was able to improve it.

(Jina) 
Including Sumi and Jina, four participants cited that the tutors' points of views helped them to see their essays from another person's perspective, using the terms such as "a third person's perspective" (Sumi), "others" (Jina), or "an impartial point of view" (Minwoo).

In spite of these positive attitudes that most participants showed towards tutor feedback, the low incorporators reported more difficulties and concerns with incorporating tutor feedback than the high incorporators; while only one high incorporator pointed out a problem in incorporating tutor feedback, five did in the group of low incorporators. This suggests that, compared to high incorporators, low incorporators seem to have more negative views toward tutor feedback. For example, Yemi, one of the low incorporators, complained that her first tutor tried to correct the topic of her essay.

The first tutor tried to change the topic of my essay, so I could not accept his feedback. So I liked the second tutor better, for she tried to fix problems without touching the basic framework of my essay.

(Yemi)

Due to the experience she had with the first tutor's feedback, Yemi stated, "in revision, I did not incorporate the tutor's feedback on the contents or on the flow of the writing." The higher incorporation rate that she showed in her second writing assignment (0.4167) confirms her preference towards her second tutor's feedback, which she evaluated as more helpful than the first tutor's.

In particular, Donghoon, who had the lowest incorporation rate of tutor feedback (0.1111), is one of the participants who strongly represented discontent towards tutor feedback.

Tutor feedback was not as good as I expected. She merely underlined the grammatical mistakes without providing other comments. I had difficulties in accepting tutor feedback because she did not comment on the content, completeness of my essay, or where to fix. (Donghoon)

As seen in the excerpt, Donghoon expressed complaints about tutor feedback directly, using words such as "not good" or "did not comment." As a result of his disappointment with tutor feedback, Donghoon refused to receive any tutor feedback on his second writing assignment.

The analysis of student perceptions on tutor feedback indicates that, although most students valued tutor feedback, dissonance between students and tutors will more likely lead to low acceptance of tutor feedback. This can be seen in the examples by low incorporators, including those by Yemi and Donghoon; when they could not agree with the tutors, it was harder for them to accept tutor feedback.

\section{DISCUSSION AND CONCLUSION}

The analysis of tutor feedback incorporation by error type reveals that the more often the students received each type of feedback, the more they incorporated them in their revisions. However, students were more likely to incorporate tutors' content-related feedback than the grammar-related ones, which suggests that tutors should focus on the contents of a student's essays when preparing their feedback, as Vengadasamy (2002) suggested similarly on teacher feedback. On the other hand, classification by feedback style does not necessarily show a relationship between frequency and incorporation rate as shown in error type classification. Although tutors gave a lot of direct feedback and indirect-coded type of feedback, their ranks in incorporation rates were not as high as the other less-frequently given types of feedback such as direct error location, indirect error location-coded, and indirect feedback. The results 
of chi-square tests on coded and uncoded groups as well as on direct and indirect groups show that coded feedback and indirect feedback lead to more significant amount of incorporation in students' revisions than the uncoded and direct ones.

The analysis of the responses to the questionnaire, which was designed to see what students think of tutor feedback and whether there exists any difference between high and low incorporators in their perceptions, reveals that most students evaluated tutor feedback quite positively, as shown in previous studies (Nicol \& MacFarlane-Dick 2006; Sadler, 1989; Sendziuk, 2010; Taras, 2003, 2006). The participants of this study thought that tutor feedback complements what they think are their weaknesses, which confirms what Taras $(2003,2006)$, Sadler (1989) and Sendzuik (2010) found among their participants' perceptions on tutor feedback. Also, the participants of this study noted that a new point of view from their tutors was the other advantage of tutor feedback. Despite these positive attitudes towards tutor feedback in general, it was also found that low incorporators were more likely to have negative experiences with incorporating tutor feedback in their revisions. This has often been pointed out as problems regarding feedback by other scholars such as Hyland (2013), Orsmond and Merry (2010), and Weaver (2006). In this study, the negative views the low incorporators demonstrated in their questionnaire may lead to their low acceptance of tutor feedback in the revisions. These results imply that tutor feedback should correspond with the students' minds; in particular, the analysis of student incorporation suggests that tutors should be aware that students may be more responsive to certain types of tutor feedback-e.g., content-oriented feedback, coded, and indirect types of feedback - than other types of feedback.

Because this study was conducted on a small scale of participants in a specific context of Korea where English is taught as a foreign language, there is a limitation in generalizing the findings to broader contexts. Despite this limitation, the results of this study indicate to future studies that it is vital to examine not only students' perceptions towards tutor feedback, but also their incorporation of tutor feedback into their revisions in order to comprehensively understand how they respond to tutor feedback. It is quite certain that students accept some types of tutor feedback better than other types of feedback. Being aware of this propensity, tutors may be more successful in helping their students to engage in the academia with their feedback. Additionally, this study suggests that it is equally important for tutors to identity what students want from their feedback in order to facilitate student incorporation of their feedback. Many students who are learning writing in English as an FL or SL have been reported to have been struggling with English writing (Ansarimoghaddam \& Tan, 2014; Singh, 2016). Tutor feedback may help them to handle these kinds of struggles that English language learners might have. However, as seen in this study, unless their feedback satisfies the students' expectations, tutors' time-consuming hard work to provide feedback may not be reciprocated by student incorporation of it. Further studies that extend the scope of studies to a wider variety of contexts and populations of students and tutors can provide insights on the understanding of tutor feedback.

\section{ACKNOWLEDGEMENT}

This work was supported by Hankuk University of Foreign Studies Research Fund of 2018.

\section{REFERENCES}

Aljaafreh, A. \& Lantolf, J. P. (1994). Negative Feedback as Regulation and Second Language Learning in the Zone of Proximal Development.Modern Language Journal. 78(4), 465-483.

Ansarimoghaddam, S. \& Tan, B. H. (2014). Undergraduates' Experiences and Attitudes of 
Writing in L1 and English. GEMA Online ${ }^{\mathrm{TM}}$ Journal of Language Studies. 14(1), 7-28. Bloxham, S. \& Boyd, P. (2012). Accountability in Grading Student Work: Securing Academic Standards in a Twenty-first Century Quality Assurance Context. British Educational Research Journal.38, 615-634.

Cho, S. \& Kim, S. (2017). L1 Translation as Scaffolding in Tutor Talk: a Case Study of Two Korean Tutors. GEMA Online ${ }^{\circledR}$ Journal of Language Studies. 17(2), 15-32.

Court, K.\& Johnson, H. (2016). Whose Job is It? Exploring Subject Tutor Roles in Assessing Students' Academic Writing via Essay Feedback. International Journal of Teaching and Learning in Higher Education. 28(1), 18-29.

Ferris, D. R. (2006). Does error feedback help student writer? New evidence on the short and long-term effects of written error correction. In K. Hyland \& F. Hyland (Eds.), Feedback in Second Language Writing: Contexts and Issues (pp. 81-104). Cambridge: Cambridge University Press.

Goldstein, L. \& Conrad, S. (1990). Student Input and Negotiation of Meaning in ESL writing Conferences. TESOL Quarterly. 24(3), 443-460.

Harris, M. (1995). Talking in the Middle: Why Writers need Writing Tutors. College English. $57,27-42$.

Hyland, K. (2013). Student Perceptions of Hidden Messages in Teacher Written Feedback. Studies in Educational Evaluation. 39, 180-187.

Nicol, D. J. \& MacFarlane-Dick, D. (2006).Formative Assessment and Self-regulated Learning: a Model and Seven Principles of Good Feedback Practice. Studies in Higher Education. 31(2), 199-218.

Orsmond, P. \& Merry, S. (2011). Feedback Alignment: Effective and Ineffective Links Between Tutors' and Students' Understanding of Coursework Feedback. Assessment \& Evaluation in Higher Education. 36(2), 125-136.

R Core Team (2018). R: A language and environment for statistical computing. R Foundation for Statistical Computing, Vienna, Austria. URL http://www.R-project.org/.

Sadler, D. R. (1989).Formative Assessment and the Design of Instructional Systems. Instructional Science. 18(2), 119-144.

Sendzuik, P. (2010). Sink or Swim? Improving Student Learning Through Feedback and Self-assessment. International Journal of Teaching and Learning in Higher Education. 22(30), 320-330.

Singh, M. K. M. (2016).An Emic Perspective on Academic Writing Difficulties Among International Graduate Students in Malaysia. GEMA Online ${ }^{\mathbb{R}}$ Journal of Language Studies. 16(3), 83-97.

Taras, M. (2003). To Feedback Or Not To Feedback In Student Self-assessment.Assessment \& Evaluation In Higher Education. 28(5), 549-565.

Taras, M. (2006). Do Unto Others or Not: Equity in Feedback for Undergraduates. Assessment \& Evaluation in Higher Education. 31(3), 365-377.

Vengadasamy, R. (2002). Responding to Student Writing: Motivate, Not Criticise.GEMA Online ${ }^{\text {TM }}$ Journal of Language Studies. 2(1), 1-9.

Weaver, M. R. (2006). Do Students Value Feedback? Student Perceptions of Tutors' Written Response.Assessment and Evaluation in Higher Education. 31(3), 379-394.

Williams, J. (2004). Tutoring and Revision: Second Language Writers in the Writing Center. Journal of Second Language Writing. 13(3), 173-201. 


\section{ABOUT THE AUTHORS}

Sookyung Cho is an associate professor in the Department of English Linguistics and Language Technology at Hankuk University of Foreign Studies, Seoul, Korea. As a graduate of the University of Wisconsin, Madison (Ph.D. Second Language Acquisition, 2008) and the University of Hawaii, Manoa (M.A. Second Language Studies, 2002), Sookyung Cho has a strong interest in second language writing, in particular, English language learners' perceptions and attitudes towards peer and teacher feedback.

Chanho Park is an assistant professor in the Department of Education at Keimyung University in Dague, Korea. He holds an MA in ESL from the University of Hawaii at Manoa and a Ph.D. in Educational Psychology (Quantitative Methods) from the University of Wisconsin-Madison. His research interests include language testing, formative assessment, psychometrics, and quantitative research methods. 